\title{
The Effect of Dispersoids on Recrystallization Behavior of Al-Er and Al-Er-Zr Alloys at Different Aging State
}

\author{
Jie $\mathrm{Hou}^{1, \mathrm{a}}$, Shengping Wen ${ }^{1, \mathrm{~b}}$, Xiaolan $\mathrm{Wu}^{1, \mathrm{c}}$, Kunyuan Gao ${ }^{1, \mathrm{~d}}$, Hui Huang ${ }^{1, \mathrm{e}}$, \\ Wei Wang ${ }^{1, f}$, Zuoren Nie ${ }^{1, g}$ \\ ${ }^{1}$ School of Material Science and Engineering, Beijing University of Technology, Pingleyuan 100, \\ Chaoyang District, Beijing 100124, People's Republic of China \\ ahoujie01@emails.bjut.edu.cn, b ${ }^{*}$ spwen@bjut.edu.cn, ‘xiaolan.wu@bjut.edu.cn, \\ dgaokunyuan@bjut.edu.cn, ${ }^{\mathrm{e}}$ huanghui@bjut.edu.cn, ${ }^{\mathrm{f}}$ wangwei@bjut.edu.cn, ${ }^{9}$ zrnie@bjut.edu.cn
}

Keywords: aluminum alloy; recrystallization; Erbium; Zirconium

\begin{abstract}
The recrystallization behaviors of Al-Er and Al-Er-Zr alloy at different aging states have been investigated. The results indicate that the recrystallization temperature of Al-Er-Zr alloy is significantly higher than that of Al-Er alloy. Al-Er-Zr alloy at over aged state after $60 \%$ cold rolled has the highest recrystallization temperature.
\end{abstract}

\section{Introduction}

The strength of aluminum alloys at elevated temperature can be improved by the formation of thermal-resistant precipitates by addition of Sc or Zr [1,2]. Composite addition of Sc and $\mathrm{Zr}$ can enhance the precipitation strengthening and thermal stability of the alloy due to the formation of core/shell structured $\mathrm{Al}_{3}(\mathrm{Sc}, \mathrm{Zr})$ dispersoids [2,3]. Er is a cheaper yet effective alternative element of expensive $\mathrm{Sc}$, the addition of $\mathrm{Er}$ is also capable of precipitation strengthening due to the formation of $\mathrm{Al}_{3} \mathrm{Er}$ dispersoids [1,4]. Previous research has revealed a synergetic effect between $\mathrm{Er}$ and $\mathrm{Zr}$ on the precipitation hardening of $\mathrm{Al}-\mathrm{Er}-\mathrm{Zr}$ alloys with the formation of $\mathrm{Al}_{3}(\mathrm{Er}, \mathrm{Zr})$ dispersoids $[4,5]$.

A dense distribution of thermally stable dispersoids can not only give a significant contribution to strength of alloys by precipitation strengthening, but also stabilize the subrain structure by exerting Zener-drag on subgrain boundaries, thus preventing recrystallization [6,7]. There are two different conditions under which dispersoids can form to prevent recrystallization [6]. One is that dispersoids have been formed in the alloys before deformation [8,9]. Another is that dispersoids nucleate and grow before recrystallization takes place during annealing [10,11]. In this paper, we investigated the recrystallization behaviors of Al-Er and Al-Er-Zr alloys at different aging states.

\section{Experimental procedures}

The experimental alloys were prepared by ingot metallurgy method. The chemical composition was verified using X-ray fluorescence spectroscopy as shown in table 1 . All the samples were firstly solutionized in air at $640^{\circ} \mathrm{C}$ for $24 \mathrm{~h}$, then quenched in water to room temperature, and aged in air isochronally with increments of $25^{\circ} \mathrm{C}$, each lasting $3 \mathrm{~h}$. For Al-Er-Zr alloys, the samples were aged isochronally from $150^{\circ} \mathrm{C}$, terminating at $375^{\circ} \mathrm{C}$ (under aged state), $425^{\circ} \mathrm{C}$ (peak aged state) and $500^{\circ} \mathrm{C}$ (over aged state). For Al-Er alloys, the samples were aged isochronally from $150^{\circ} \mathrm{C}$ to $300^{\circ} \mathrm{C}$. After that, all the samples were cold rolled to $60 \%$ and followed by isothermal annealing at different temperatures for one hour. Vickers microhardness was measured on polished samples with a load of $200 \mathrm{~g}$ and a dwell time of $10 \mathrm{~s}$ with at least 10 independent measurements, and electrical conductivity was also measured with at least 10 independent measurements. Slices for transmission electron microscopy (TEM) samples were cut from the plate and were ground to less than $70 \mu \mathrm{m}$ and punched into $3 \mathrm{~mm}$ discs. Then thin foils for TEM observation were prepared by twin-jet polishing with an electrolyte solution consisting of $30 \% \mathrm{HNO}_{3}$ and $70 \%$ methanol below $-30^{\circ} \mathrm{C}$. TEM observation was carried out by using a JEOL 2010 microscope with an operating voltage of $200 \mathrm{kV}$. 
Table 1. Compositions of the Al-Er and Al-Er-Zr alloys investigated (at.\%)

\begin{tabular}{ccccc}
\hline Alloy & \multicolumn{2}{c}{ Nominal composition } & \multicolumn{2}{c}{ Verified compostion } \\
\cline { 2 - 5 } & $\mathrm{Er}$ & $\mathrm{Zr}$ & $\mathrm{Er}$ & $\mathrm{Zr}$ \\
\hline Al-0.04Er & 0.04 & - & 0.049 & - \\
Al-0.04Er-0.08Zr & 0.04 & 0.08 & 0.037 & 0.085 \\
\hline
\end{tabular}

\section{Results and Discussion}

Fig. 1 shows the evolution of microhardness and electrical conductivity of Al-Er and Al-Er-Zr alloys at peak aged states after cold rolled to $60 \%$ during recrystallization annealing process. Assuming that the temperature at which microhardness drops suddenly is the recrystallization temperature. As shown in Fig. 1(a), the recrystallization temperature of Al-Er-Zr and Al-Er alloys are $475^{\circ} \mathrm{C}$ and $325^{\circ} \mathrm{C}$. From Fig. $1(\mathrm{~b})$, one can find that the electrical conductivity of Al-Er alloy did not change obviously with the increase of temperature, in contrast to Al-Er-Zr alloys whose electrical conductivity decrease rapidly at elevated temperature, indicating the dissolution of dispersoids [2]. And this also indicates that the influence of precipitation or dissolution of $\mathrm{Zr}$ atoms on electrical conductivity are greater that Er. For Al-Er-Zr alloy, because of the synergetic effect of Er and $\mathrm{Zr}$, the volume fraction and number density of the precipitates is higher than that of binary Al-Er alloy, and the thermal resistance of $\mathrm{Al}_{3}(\mathrm{Er}, \mathrm{Zr})$ precipitates are higher than $\mathrm{Al}_{3} \mathrm{Er}[4,5]$, which result in the higher recrystallization temperature. According to previous research, Al-Er alloy reaches peak harness at $300^{\circ} \mathrm{C}$, then decrease at higher temperature because of rapid coarsening of $\mathrm{Al}_{3} \mathrm{Er}$ dispersoids [5]. Therefore, $\mathrm{Al}_{3} \mathrm{Er}$ dispersoids cannot retard recrystallization process effectively at elevated temperature, with the consideration of more rapid coarsening rate of $\mathrm{Al}_{3} \mathrm{Er}$ dispersoids due to dislocation pipe diffusion mechanism.


Fig. 1 (a) Vickers microhardness and (b) electrical conductivity evolution during recrystallization annealing of $60 \%$ cold rolled peak aged Al-Er and Al-Er-Zr alloys

Fig. 2 shows the evolution of microhardness and electrical conductivity of Al-Er-Zr alloys during recrystallization annealing. At the beginning, the microhardness at peak aged state is obviously higher than other three aging states at as-rolled state due to the high number density and small size of $\mathrm{Al}_{3}(\mathrm{Er}, \mathrm{Zr})$ dispersoids obtained from peak aging treatment [4,5]. The low number density of dispersoids at under aged state, the effect of coarsening of dispersoids at over aged state, and the lack of dispersoids at solutionized state leads to the low microhardness. It can be seen from Fig. 2(a) that the recrystallization temperature are $525^{\circ} \mathrm{C}, 475^{\circ} \mathrm{C}, 425^{\circ} \mathrm{C}$ and $400^{\circ} \mathrm{C}$ for over aged state, peak aged state, solutionized state and under aged state respectively. For over aged state, although the microhardness is lower than that of peak aged state [5], the size and number density of the dispersoids may be more effective on retarding recrystallization. For under aged state, the volume fraction of dispersoids is not high enough to strongly retard recrystallization. 

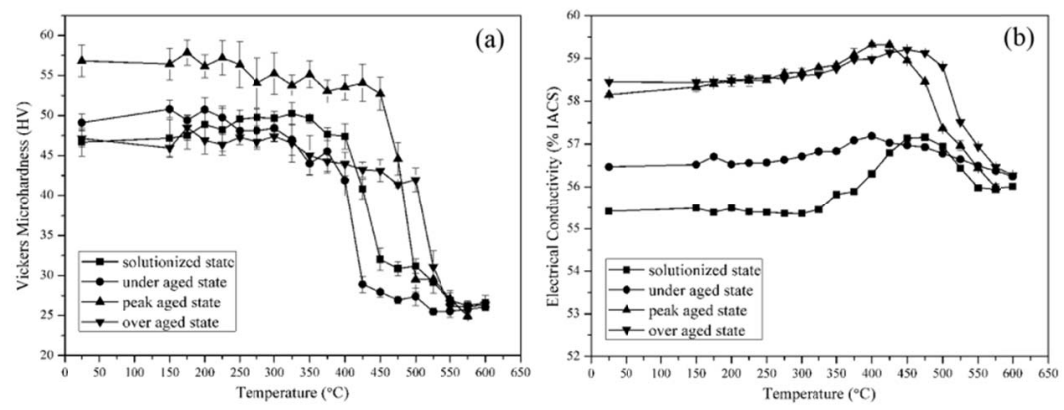

Fig. 2 (a) Vickers microhardness and (b) electrical conductivity evolution during recrystallization annealing of $60 \%$ cold rolled Al-Er-Zr alloys with different aging states

For solutionized state, the recrystallization temperature is higher than that of under aged state, but there is no $\mathrm{Al}_{3}(\mathrm{Er}, \mathrm{Zr})$ precipitate exist in $\mathrm{Al}$ matrix at as-rolled state. As shown in Fig. 2(b), the electrical conductivity of the alloy increase gradually with the increase of annealing temperature due to precipitation. For solutionized state, the increment of electrical conductivity is obviously higher than other three states. After cold rolling, many dispersoids homogeneously nucleated on dislocations during annealing, which interfere with the recrystallization process [11]. The supersaturation degree of $\alpha$-Al matrix for solutionized state is the highest, which leads to the strongest strain induced precipitation effect compared to other states. At elevated temperature, there are continuous decrease in electrical conductivity, which is due to dissolution of the $\mathrm{Al}_{3}(\mathrm{Er}, \mathrm{Zr})$ dispersoids [2].

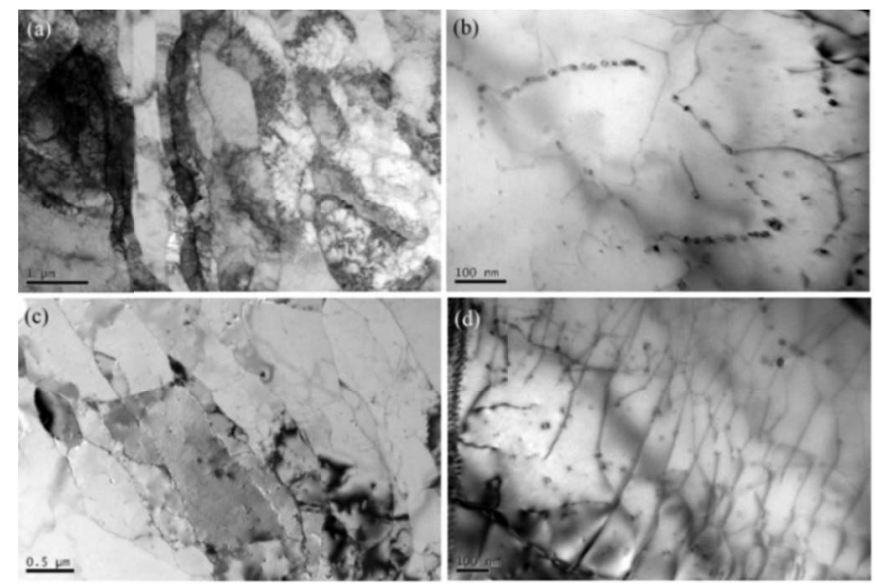

Fig. 3 TEM micrographs of $60 \%$ cold rolled over aged Al-Er-Zr alloys after recrystallization annealing for 1 hour: (a) the subgrain structure at $250^{\circ} \mathrm{C}$; (b) precipitates at $250^{\circ} \mathrm{C}$; (c) the subgrain structure at $425^{\circ} \mathrm{C}$; (d) precipitates at $425^{\circ} \mathrm{C}$

Fig. 3 shows the TEM micrographs of $60 \%$ cold rolled over aged Al-Er-Zr alloys after recrystallization annealing for 1 hour at $250^{\circ} \mathrm{C}$ and $425^{\circ} \mathrm{C}$. Fig. 3(a) and 3(c) depict the subgain structure which indicates that only recovery occurred during annealing process. Fig. 3(b) and 3(d) are the magnification of Fig. 3(a) and 3(c). It can be found that there are many nanoscaled precipitates, and plenty of dislocations distribute near these precipitates. These indicate that the precipitates impede the dislocation movement, thus retard the recrystallization process.

\section{Summary}

The recrystallization behaviors of Al-Er and Al-Er-Zr alloys at different aging states have been investigated by microhardness tests, electrical conductivity tests and TEM. The recrystallization temperature of Al-Er-Zr alloy is significantly higher than that of Al-Er alloy. Al-Er-Zr alloy at over aged state after $60 \%$ cold rolled has the highest recrystallization temperature. And for solutionized state, the recrystallization temperature is close to peak aged state due to the strain induced precipitation which retards recrystallization process. 


\section{Acknowledgements}

This work was supported in part by the National Key Basic Research\& Development Plan Project (No. 2012CB619503), National and Beijing Natural Science Foundation Project (No. 51201003 and No. 2142007), the National High Technology Research and Development Program (No. 2013AA031301).

\section{References}

[1] K.E. Knipling, D.C. Dunand, D.N. Seideman: Z. Metallkd Vol. 97 (2006), p. 246

[2] K.E. Knipling, R.A. Karnesky, C.P. Lee, D.C. Dunand, D.N. Seideman: Acta Mater Vol. 58 (2010), p. 5184

[3] C. Booth-Morrison, D.C. Dunand, D.N. Seidman: Acta Mater Vol. 59 (2011), p. 7029

[4] H. Huang, S.P. Wen, K.Y. Gao, W. Wang, Z.R. Nie: Metall. Mater. Trans. A Vol. 44 (2013), p. 2849

[5] S.P. Wen, K.Y. Gao, Y. Li, H. Huang, Z.R. Nie: Scripta Mater Vol. 65 (2011), p. 592

[6] J. Royset, N. Ryum: Inter. Mater. Rev Vol. 50 (2005), p. 19

[7] B. Forbord, L. Auran, W. Lefebvre, H. Hallem, K. Marthinsen: Mater. Sci. Eng. A Vol. 424 (2006), p. 174

[8] R. Roumina, C.W. Sinclair: Acta Mater Vol. 58 (2010), p. 111

[9] Z.H. Jia, J. Royset, J.K. Solberg, Q. Liu: Trans. Nonferrous. Met. Soc. China Vol. 22 (2012), p. 1866

[10] S.S. Hansen, J.B. Vander Sande, M. Cohen: Metall. Trans. A Vol. 11 (1980), p. 387

[11] M.J. Jones, F.J. Humphreys: Acta Mater Vol. 51 (2003), p. 2149 